\title{
Working conditions and interventions of Health extension workers in the rural areas of South-Western Ethiopia
}

\author{
Gudina Yadeta * \\ Assosa University. \\ PO Box 18, Assosa, Benishangul-Gumuz, Ethiopia. \\ gyadeta12@gmail.com \\ * Corresponding Author
}

\section{ARTICLE INFO}

\section{Article History}

Received:

19 August 2019;

Revised:

31 October 2019;

Accepted:

21 January 2020

\section{Keywords}

Working conditions;

Interventions;

Health extension

workers

\begin{abstract}
Working conditions of health care workers considerably affect the delivery of health care services. This study examined working conditions and interventions of Health Extension Workers in the selected kebeles of Sarbo District, South-western Ethiopia. The study employed a qualitative research approach with a case study design. Being informed by-depth interview, a researcher collected primary data from four health extension workers and a health officer of the district. The researcher analyzed and interpreted primary data thematically. Findings of the study indicated that low payment, poor transportations, unsafe working conditions, and less-supportive top management were among the restraining challenges that impede interventions and working conditions of health extension workers in the study areas. These constraining factors further lead to poor delivery of primary health care services. Therefore, this study recommends effective policy interventions to bring favorable working conditions for rural health extension workers.
\end{abstract}

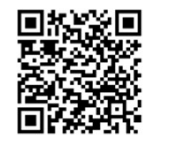

This is an open access article under the $\underline{\mathrm{CC}-\mathrm{BY}-\mathrm{SA}}$ license.

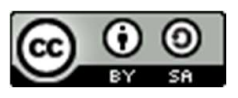

\section{INTRODUCTION}

Across the world, income, skills, and commitments are among critical conditions for the delivery of excellent quality health care services (Serneels, Montalvo, Pettersson, Lievens, Butera, $\&$ Kidanu, 2010). Arguably, favorable working conditions are helpful for health workers' motivation, which in turn determines the quality of health care services delivery (Songstad, Rekdal, Massay, \& Blystad, 2011; Anand \& Barnighausen, 2004). However, unsafe work-ing conditions make workers not to feel concern and make them have a sense of isolation from the organization they work in (Farahbod, Azadehdel, Chegini, \& Ashraf, 2012). The recruitment and retention of health workers in both the public and private sectors of the local market depend on the financial and non-financial rewards. This is the reason why attracting health workers to rural areas remains a particular challenge in developing countries (Yamey, 2007). Thus, as World Health Organization (2006) asserted, the geographic distribution of (urban versus rural) health workers remains a significant constraint in improving health services in developing countries.

For instance, rural areas of Ethiopia, where the majority of the population live, have been highly subjected to a chronic shortage of health workers; thus, the people have been suffering from communicable diseases. In reaction to this, the Health Extension Programme was launched in 2003 in the country to promote the health of its communities by building trained human resources (health workers). The program has about four components: disease prevention and control, family health, hygiene, and environmental sanitation, and health education and communication (Kok, Kea, Datiko, Broerse, Dieleman, ... \& Taegtmeyer, 2015; Mirkuzie, Sisay, Reta, \& Bedane, 2014; World Health 
Organization, 2006). Moreover, the objective of this program is all about improving primary health services in rural areas via an innovative community-based approach by giving paramount weight on prevention, healthy living, and primary curative care (Mirkuzie, Sisay, Reta, \& Bedane, 2014;, 2014; Tilahun, Hanlon, Fekadu, Tekola, Baheretibeb, \& Hoekstra, 2016).

Nemcek and Sabatier (2003) stated that health extension workers comprised of local community members in that they could build up culturally relevant and highly accessible health materials and information that can mitigate blockage to health care quality. With this fact in mind, in Ethiopia, health extension workers haven recruited from local communities in which they assigned to work. However, the working conditions and interventions of health extension workers in the country characterized by challenges, including limited infrastructure, transpiration problems, and the distance from health posts (Olson \& Piller, 2013). It was evident that addressing the quality of health services in a country demands an emphasis on the determinants of health care services provision. Furthermore, taking into consideration health extension workers' commitment, motivation, and satisfaction (i.e., their working conditions) does not deviate from this fact. health extension workers' working conditions and interventions in rural areas of the study sites, Kallacha and Awaysabbu kebeles in Sarbo woreda, Jimma Zone, did not get the attention of researchers. This problem has become a significant issue in the decline in the level of medical treatment for workers. Handling by the government also tends to be ignored inseparable from the problem of funds and much funding. Therefore, the current study focused on addressing this issue. The objectives of the study were concerned with stating the working conditions of health extension workers, describing the interventions of health extension workers, and identifying challenges and opportunities of health extension workers in delivering primary health care services in rural settings of the study areas.

\section{METHOD}

The study sites were Kallacha and Awaysabbu, in Sarboworeda, Jimma zone of Oromia National Regional State. Both the woreda and the two study sites or kebeles were purposely selected based on the research, as mentioned earlier gap. Sarbo woreda found at $18 \mathrm{~km}$ distance from Jimma, the town of the zone, and the selected kebeles are located at $15 \mathrm{~km}$ away from the Sarbo, Town of the woreda. Moreover, the targeted individuals in this study were health extension workers in the selected kebeles, who have been giving services to the local community. Kebele is the smallest governmental administrative unit, which has a population of about 5000 people on average. As Koblinsky, Tain, Gaym, Karim, Carnell, \& Tesfaye (2010) explain, in Ethiopia, two young females are recruited (by the committee in collaboration with the local community) per each kebele to give one-year training before employing them in the position of health extension workers permanently. Accordingly, each kebele has two health extension workers who give primary health care services, including hygiene and sanitation. Females are recruited due to the fact that health extension program packages deal mostly with issues affecting mothers and children. Thus, communication expected to be more comfortable between mothers and health extension workers. Also, since they know the living conditions of their local people and the values and norms of their community in which they live, they might perform their duties better than strangers might do. The reason behind focusing on health extension workers in this study is that the research directly focuses on their working conditions and interventions in delivering primary health care services to the local community. The study employed a qualitative approach. Accordingly, as a method of data collection, an in-depth interview was employed with four female health extension workers from the two kebeles. The researcher gathered data in January, 2017 and he analyzed the data thematically.

\section{FINDINGS AND DISCCUSIONS}

The Intervention of Health Extension Workers in the Study areas

Health extension workers (HEWs) encourage community members to take charge of their health via education campaigns and raising awareness regarding health issues (Mirkuzie, Sisay, Reta, $\&$ Bedane, 2014). They work the process of empowering the community through creating enabling 
conditions (Workie \& Ramana, 2013). HEWs are the principal actors in ensuring the well-being of people, which is a precondition for the enjoyment of life and for the most excellent productivity (Desta, Shifa, Dagoye, Carr, Van Roosmalen, Stakelenburg, ... \& Kim, 2017). Accordingly, in this study, one of health ex-tension workers, 23 years old, from Kallacha kebele stated that:

"I should make sure that all people in my area are doing what they have been learned from agriculture and health extension workers. I encourage people to create and use latrines; make leaky tiny for washing, and use malaria nets. I do emphasis on hygiene and sanitation in the households".

Besides, her information illustrates that she makes follow up that enables her to provide a report to the woreda health office regularly. As she said, the report aims at identifying the existing weaknesses, challenges, and successes. Similarly, information from the key informant interview from Sarbo Health Center indicates that a regular report from rural extension workers on the health status of the rural community, especially pregnant mothers and children's health-related issues are needed for improvements and enhancements of the services. Furthermore, regarding the result of their interventions, health extension worker from Awaysabbuu, 22 years old, expressed that:

"We have seen an impressive improvement in the health of children by tackling major causes of diseases and childhood illnesses which are made possible by rural health care services. We have been making people more responsible for controlling diseases and thereby to improve their health".

In line with the above expression, Kok et al., (2015) and Mirkuzie, Sisay, Reta, and Bedane (2014) stated that through extension programs, the actors, health extension and agriculture extension workers in collaboration with the local community, made a significant contribution in improving health outcomes of people. The interventions undertaken by these actors are multi-dimensional and participatory. They play essential roles in providing education on family planning, sanitation, and hygiene (Woldie, Morankar, Feyissa, Labonte, \& Sanders, 2015). For instance, health extension worker from Kallacha, Kebele, 19 years old age, said:

"Routinely, I go to surrounding households, and I teach them health and health-related matters to maintain or improve their health and enhance their human capital so that they may sustainably use the service, inputs, and information provided through agricultural extension. Here, personal hygiene, sanitation, and nutrition improvements are my principal works".

Depending on the above information provided by health extension workers, one can understand that health extension workers have been working on basic issues in collaboration with the local community, and they have been serving the community in improving their health and lives. Another Health Extension Worker (HEW) 22 years old, from Awaysabbuu also stated that her responsibilities do not deviate from the above-stated shores. Therefore, creating an enabling environment for the health workers is imperative to enhance the quality services they provide for the community and to make the services sensitive to the health needs of the less privileged rural groups (women and children) who represent the overwhelming majority of the population and are the major potential productive forces of the country (Banteyerga \& Kidanu, 2008).

\section{Challenges of Health Extension Workers in the Study Areas}

Health extension workers often face different constraining and enabling factors in their intervention in providing primary health care services, especially for the rural community (Workie \& Ramana, 2013). Of course, as it can be understood from the informants' expressions, even though there are some favorable conditions that can help the provision of the primary health care services, there are different impeding factors, including inadequate availability of necessary materials and facilities. This expression corroborates with the findings of Olson and Piller (2013) that stressed the constraining factors such as poor infrastructure development (road), transpiration problems as a result of limited vehicles and the distance from health posts during emergencies. The HEP encounters several challenges including inability to ensure quality services, enriching the skills and performance of HEWs especially in the area of maternal health and retaining the program with proper carrier 
framework for the HEWs (Workie \& Ramana, 2013; Feysia, Herbst, \& Lemma, 2012) opine that high workload and low financial rewards are among the factors that make health workers not to feel satisfaction. With the similar interview another informant, 23 years old, from Kallacha, Kebele said "In our case, you can find meaning at work (i.e., helping the less fortunate, during emergency cases, making better the condition of grassroots communities), yet it is an illusion to get satisfactory payment in cash. There is no financially oriented pleasure from our work to improve ourselves. Plus, the work is full of a challenge with the absence of/ poor provision of logistic".

Most farmers (about 80 percent) in rural areas of Ethiopia do not have latrine (EDHS, 2011).In this study, informants stated that there is a huge gap in terms of providing adequate water for toilet services. Therefore, attention has to taken to the provision of water because it is impossible to maintain the health of the people without having access to water. The In-depth interview further indicated that People in the area are still suffering from environmental-related health challenges associated with insufficient access to clean drinking water, inadequate sewerage facilities, and poor solid waste disposal. These remain as major challenges that constrain the intervention of HEWs. One of the health extension workers from Awaysabbuu, 22 years old, said that:

"A Limited hand washing after visiting the toilet remains the fundamental challenges. When people go to latrines, they face discomfort because the availability of water is limited. Really, the problem of water around the toilet is a serious problem that people are facing. Additionally, regarding our intervention, some people are not responsive (e.g., regarding family planning)".

Working conditions involve several positive and negative components that influence workers relationship, quality of services, their sprit and etc. working schedule, work load, leisure, remuneration, emotional attachments, physical conditions are among the elements of working conditions (Hemström, 2001; Bakotic \& Babic, 2013). Studies in Ethiopia revealed distances among several isolated villages, and much workload makes service delivery too tiresome and resulted in dissatisfaction of HEWs with their interventions (Banteyerga \& Kidanu, 2008). Even though HEWs are expected to work 25 percent of their time at the health post and 75 percent at community and household levels (Bhutta et al., 2010), they spend much time in waiting for patients and clients in health posts instead of direct health education and service provision in rural areas (Tilahun et al., 2016). Health extension workers (19 years old) from Kallacha asserted that:

less flexible working hours, much workload, and less supportive top management are some of the challenges I have been facing. The situations in which I'm found force me to undertake responsibilities. Most of the time, I spent much time at health posts through moving between patients and other health personnel.

From the above statement of health extension worker, one can understand she has a low level of job satisfaction and less motivated toward her work. Her dissatisfaction is highly related to her working conditions. This may further impede effective health service delivery. Moreover, another health extension worker from Awaysabbuu added the following:

"I have been working all the days, but I am paid less than what I need to deserve. The working condition is not attractive, owning to low payment. Apart from this, I move long distances in the absence of vehicles. The condition becomes boring, especially during the season of rain. I feel I'm overlooked and neglected".

Similarly, information from the key informant interview from Sarbo Health Center indicates that infrastructure development is poor in the area. Addressing poor health service is futile without focusing on an individual's working conditions who work in health organizations (World Health Organization, 2006). In order to bring the desired change in health care services, supportive working condition is enormously helpful (Farahbod, Azadehdel, Chegini, \& Ashraf, 2012). Supportive working conditions surpass providing adequate utensils and supplies; rather, it involves smooth interactions of workers in which they can exchange information and make decisions. Apart from this, having effective communication with management, taking consideration about workload, and creating responsiveness is imperative (Ali, Ali, \& Adan, 2013). According to an in-depth interview with four HEWs, the already deep-seated problems hampered the interventions. That means when 
many more people suffer from hunger, poverty, and malnour-ishment, it remains an existential challenge to achieve goals of the Health Extension Program. As The United Nations (2018) problems of food safety, lack of dietary diversity, suboptimal hygiene, and limited access to quality nutrition services are among social pathologies resulting in poor health conditions. Therefore, such problems as poverty deteriorated living standards and the like significantly contribute to health problems (Yamey, 2007).

By recognizing rapid population growth as the major challenge in poverty reduction, the government tries to balance population growth with economic growth through contraceptive methods. Health extension workers and other agencies play their role in providing education on family planning. However, population growth still taking tempo (Sellen, Sharif, Tefera, \& Hyder, 2012). Drawing on community survey about Health Extension Program on family planning, Feysia, Herbst, and Lemma (2012) revealed that about 60 percent of the respondents were satisfied with the services given by workers, and they believe in intervention has brought a change in controlling fertility. However, the prevalence rate of contraceptive methods remains pathetic (29\%), which was by far less than half of the planned 66 percent to be achieved in 2015. Teklehaimanot and Teklehaimanot (2013) in this study, one informant, 18 years old, from Awaysabbu raised the issue as the ongoing challenge to rural health extension program as follows:

"We provided education on family planning. Nevertheless, people continue to have several children. Religion does not allow them to limit the number of their family numbers by using contraceptive methods. From a religious point of view, using the contraceptive method is conceived as a major sin, and it is considered an abomination act. Fertility control is considered a disturbing natural law, which is all about breaking the rules and regulations of the scripture".

Another informant (19 years old) from Kallacha stated that family planning is very poor in our village. Marrying more than one wife as it is supported by region in Islam with the idea that having many children as social security makes the progress of family planning sluggish. Therefore, failure to implement family planning will adversely affect the progress of overcoming communicable diseases through the empowerment of individuals, households, and communities. People in the study area pursue their livelihood from small scale agriculture. Thus, as the population increases drastically with the ongoing being reluctant to conceptive methods, meeting food demand, promoting health, and preventing diseases become cumbersome

\section{Opportunities for Health Extension Workers in the Study Areas}

The government has placed special attention on the integration between agriculture and health extension packages in improving the well being of less-privileged farmers in the country (The United Nations, 2018). With a similar token, key informant interviewee from woreda health posts illustrates that both health and agriculture extension workers endeavor for the betterment of people. He further explains in order to ensure the effectiveness of the package; supervisors are assigned to follow the performance of HEWs. However, as per to in-depth interview with HEWs, there was less and less good supervision. HEW (23 years old) from Kallacha stated that "no meaningful supervision is there; the supervisor needs a report without supporting us. For them, what matters a lot is a report at the expense of everything." Regarding the current opportunities, informant 18 years of age, from Awaysabbuu, stated:

"I do have a strong relationship with the surrounding community. People themselves are the principal drivers concerning their health issues. Except for some individuals, they provide a comfortable situation in our intervention process. Especially, the role of model farmers cannot be overlooked".

In addition, another Health extension worker from Kallacha said, "In our intervention process, we have linkage with community, religious, and cultural leaders, school and other social organizations." The above ideas imply that the collaborative relationship between health extension workers and community enhance health and prevent health problems. However, when some individuals from the community fail to cooperate with health extension workers, it can be challenging in achieving the cherished goals. The interaction among heath extension workers with rural people 
is not necessarily divorced from the established framework of social relations. That means the nature of contact between extension workers and rural communities often takes place within a specific socio-cultural environment and often limits/promotes the community's access to medical facilities and information.

\section{CONCLUSION}

In Ethiopia, health extension workers play fundamental roles in providing primary health services in rural areas in line with intervention packages. Similarly, in this study, it would be safe to argue that health extension workers in the study area have been playing critical roles in addressing the health problems of their community. However, constraining factors that need interventions from the concerned bodies found. These impeding factors involve unsafe working conditions such as high workload, distances among isolated kebeles, low payment, and the others. These problems put barriers to the interventions of health extension workers in the study areas. Therefore, it would be futile to enhance the wellbeing of the community at grass root level without addressing unfavorable working conditions of health extension workers. Depending on the analysis of the study, it is apparent that infrastructures impede the opportunities of augmenting rural health care services. Poor road construction affected access to health and other social services. This calls for the designing of effective interventions to address rural health care service. It has been argued that favorable working condition of health work is one of the determinants in quality health care services. Yet, in this study, the interviewed health extension workers are not as satisfied with their conditions, mainly due to challenges related to incentive and weak infrastructures. Hence, policymakers should consider the allocation of materials and financial resources, infrastructures, and other important inputs for health care services in the areas.

\section{REFERENCES}

Ali, A. Y. S., Ali, A. A., \& Adan, A. A. (2013). Working conditions and employees' productivity in manufacturing companies in sub-Saharan African context: Case of Somalia. Educational Research International, 2(2), 67-78.

Anand, S., \& Bärnighausen, T. (2004). Human resources and health outcomes: Cross-country econometric study. The Lancet, 364(9445), 1603-1609. doi: https://doi.org/10.1016/S0140$\underline{6736(04) 17313-3}$

Bakotic, D., \& Babic, T. (2013). Relationship between working conditions and job satisfaction: The case of Croatian shipbuilding company. International Journal of Business and Social Science, 4(2), 206-213.

Banteyerga, H., \& Kidanu, A. (2008). Rapid appraisal of health extension program: Ethiopia country report. Addis Ababa: The L10K project and MHRC.

Bhutta, Z. A., Lassi, Z. S., Pariyo, G., \& Huicho, L. (2010). Global experience of community health workers for delivery of health related millennium development goals: A systematic review, country case studies, and recommendations for integration into national health systems. Global Health Workforce Alliance, 1(249), 1-374.

Desta, F. A., Shifa, G. T., Dagoye, D. W., Carr, C., Van Roosmalen, J., Stekelenburg, J., ... \& Kim, Y. M. (2017). Identifying gaps in the practices of rural health extension workers in Ethiopia: a task analysis study. BMC health services research, 17(1).

Farahbod, F., Azadehdel, M. R., Chegini, M. G., \& Ashraf, A. N. (2012). Work alienation historical backgrounds, concepts, reasons, and effects. Journal of Basic and Applied Scientific Research, 2(8), 8408-8415.

Feysia, B., Herbst, C., \& Lemma, W. (Eds.). (2012). The health workforce in Ethiopia: Addressing the remaining challenges. The World Bank. 
Hemström, Ö. (2001). Chapter 7. Working conditions, the work environment and health. Scandinavian Journal of Public Health, 29(58), 167-184. doi: https://doi.org/10.1177/14034948010290033701

Koblinsky, M., Tain, F., Gaym, A., Karim, A., Carnell, M., \& Tesfaye, S. (2010). Responding to the maternal health care challenge: The Ethiopian Health Extension Program. Ethiopian Journal of Health Development, 24(1), 105-109. doi: http://dx.doi.org/10.4314/ejhd.v24i1.62951

Kok, M. C., Kea, A. Z., Datiko, D. G., Broerse, J. E., Dieleman, M., Taegtmeyer, M., \& Tulloch, O. (2015). A qualitative assessment of health extension workers' relationships with the community and health sector in Ethiopia: Opportunities for enhancing maternal health performance. Human Resources for Health, 13(1). doi: https://doi.org/10.1186/s12960-015$\underline{0077-4}$

Mirkuzie, A. H., Sisay, M. M., Reta, A. T., \& Bedane, M. M. Current evidence on basic emergency obstetric and newborn care services in Addis Ababa, Ethiopia; A cross sectional study. BMC Pregnancy and Childbirth, 14(1). doi: https://doi.org/10.1186/1471-2393-14-354

Nemcek, M. A., \& Sabatier, R. (2003). State of evaluation: Community health workers. Public Health Nursing, 20(4), 260-270. doi: https://doi.org/10.1046/j.1525-1446.2003.20403.x

Olson, D. J., \& Piller, A. (2013). Ethiopia: An emerging family planning success story. Studies in Family Planning, 44(4), 445-459. doi: https://doi.org/10.1111/j.1728-4465.2013.00369.x

Sellen, D., Sharif, S., Tefera, B., \& Hyder, Z. (2012). Strengthening family planning with communitybased nutrition interventions in Ethiopia: A qualitative study. Washington: The International Bank for Reconstruction and Development / The World Bank.

Serneels, P., Montalvo, J. G., Pettersson, G., Lievens, T., Butera, J. D., \& Kidanu, A. (2010). Who wants to work in a rural health post? The role of intrinsic motivation, rural background and faith-based institutions in Ethiopia and Rwanda. Bulletin of the World Health Organization, $88,342-349$.

Songstad, N. G., Rekdal, O. B., Massay, D. A., \& Blystad, A. (2011). Perceived unfairness in working conditions: the case of public health services in Tanzania. BMC Health Services Research, 11(1). doi: https://doi.org/10.1186/1472-6963-11-34

Teklehaimanot, H. D., \& Teklehaimanot, A. (2013). Human resource development for a communitybased health extension program: a case study from Ethiopia. Human Resources for Health, 11(1). doi: https://doi.org/10.1186/1478-4491-11-39

Tilahun, D., Hanlon, C., Fekadu, A., Tekola, B., Baheretibeb, Y., \& Hoekstra, R. A. (2016). Stigma, explanatory models and unmet needs of caregivers of children with developmental disorders in a low-income African country: A cross-sectional facility-based survey. BMC Health Service Research, 16(1). doi: https://doi.org/10.1186/s12913-016-1383-9

The United Nations. (2018, April). Ethiopia's progress towards eradicating poverty. Paper presented at the Inter-Agency Group Meeting On the "Implementation of the Third United Nations Decade for the Eradication of Poverty (2018 - 2027)", Addis Ababa, Ethiopia.

Woldie, M., Morankar, S., Feyissa, G., Labonte, R., \& Sanders, D. (2015). Coverage of child health services in rural districts of Ethiopia with the health services extension program. Journal of Public Health and Epidemiology, 7(7), 223-231. doi: https://doi.org/10.5897/JPHE2015.0733

Workie, N. W., \& Ramana, G. N. (2013). UNICO studies series 10: The health extension program in Ethiopia. Washington: The World Bank.

World Health Organization. (2006). The world health report 2006: Working together for health. World Health Organization. 
8 - Harmoni Sosial: Jurnal Pendidikan IPS

Yamey, G. (2007). Which single intervention would do the most to improve the health of those living on less than $\$ 1$ per day? PLoS Medicine, 4(10), e303. doi: https://doi.org/10.1371/journal.pmed.0040303. 